\title{
Parasitic infection by larval helminths in Antarctic fishes: pathological changes and impact on the host body condition index
}

\author{
Mario Santoro ${ }^{1,2, *}$, Simonetta Mattiucci ${ }^{1}$, Thierry Work ${ }^{3}$, Roberta Cimmaruta ${ }^{2}$, \\ Valentina Nardi ${ }^{1,2}$, Paolo Cipriani ${ }^{1}$, Bruno Bellisario ${ }^{2}$, Giuseppe Nascetti ${ }^{2}$ \\ ${ }^{1}$ Department of Public Health and Infectious Diseases, Section of Parasitology, Sapienza University of Rome, \\ Piazzale Aldo Moro, 00185 Rome, Italy \\ ${ }^{2}$ Department of Ecological and Biological Sciences, Tuscia University, Viale dell'Università sn 01100 Viterbo, Italy \\ ${ }^{3}$ US Geological Survey, National Wildlife Health Center, Honolulu Field Station, PO Box 50167, Honolulu, Hawaii 96850, USA
}

\begin{abstract}
We examined pathological changes and relationship between body condition index (BCI) and parasitic infection in 5 species of fish, including 42 icefish Chionodraco hamatus (Channichtyidae), 2 dragonfish Cygnodraco mawsoni (Bathydraconidae), 30 emerald rock cod Trematomus bernacchii, 46 striped rock cod T. hansoni and 9 dusty rock cod T. newnesi (Nototheniidae) from the Ross Sea, Antarctica. All parasites were identified by a combination of morphology and mtDNA cytochrome-oxidase-2 sequence (mtDNA cox2) analysis, except Contracaecum osculatum s.l., for which only the latter was used. Five larval taxa were associated with pathological changes including 2 sibling species (D and E) of the C. osculatum species complex and 3 cestodes including plerocercoids of a diphyllobothridean, and 2 tetraphyllidean forms including cercoids with monolocular and bilocular bothridia. The most heavily infected hosts were $C$. hamatus and $C$. mawsoni, with C. hamatus most often infected by C. osculatum sp. D and sp. E and diphyllobothrideans, while C. mawsoni was most often infected with tetraphyllidean forms. Histologically, all fish showed varying severity of chronic inflammation associated with larval forms of helminths. Diphyllobothrideans and C. osculatum spp. were located in gastric muscularis or liver and were associated with necrosis and mild to marked fibrosis. Moderate multifocal rectal mucosal chronic inflammation was associated with attached tetraphyllidean scolices. C. hamatus showed a strong negative correlation between BCI and parasite burden.
\end{abstract}

KEY WORDS: Diphyllobothridean · Tetraphyllidean · Contracaecum osculatum s.l. · Antarctic fish • Ross Sea $\cdot$ Pathology

Resale or republication not permitted without written consent of the publisher

\section{INTRODUCTION}

Antarctic teleost fishes, including the icefish Chionodraco hamatus (Channichtyidae), the dragonfish Cygnodraco mawsoni (Bathydraconidae) and rock cod Trematomus spp. (Nototheniidae), may be heavily infected by a wide variety of larval forms of nematodes and cestodes (Wojciechowska 1993a,b, 1994, Orecchia et al. 1994, Zdzitowiecki 2001, Laskowski \& Zdzitowiecki 2005, Mattiucci \& Nascetti 2008). Prevalences of the nematode Contracaecum osculatum species complex (which mature in marine mammals), diphyllobothridean cestodes (which mature in birds and marine mammals) and tetraphyllidean cestodes (which mature in sharks and skates) may reach $100 \%$, with an intensity of hundreds of individuals per fish (Wojciechowska 1993a, Rocka 2003, 2006, Mattiucci \& Nascetti 2008).

To our knowledge, no data are available on the pathological changes and the impact that helminth infections may have on their teleost hosts in Antarctica. The only exception is a study by $\mathrm{O}^{\prime} \mathrm{Neill}$ et al. 
(1988), who described the chronic inflammatory response in the Antarctic silverfish Pleuragramma antarcticum to plerocercoids of a pseudophyllidean cestode identified as Diphyllobothrium spp. from the South Shetland Islands. Here, we report on the infection levels, the impact of parasitic load on their hosts and the pathological changes induced by larval helminths of the Contracaecum osculatum s.l. species complex and diphyllobothridean and tetraphyllidean cestodes in fish species from Terra Nova Bay (Ross Sea), Antarctica.

\section{MATERIALS AND METHODS}

\section{Sampling data}

During February 2012, a total of 129 specimens belonging to 5 fish species were sampled by hand line or net at benthic depths ranging from 110 to $160 \mathrm{~m}$ in front of the Mario Zucchelli Station in Terra Nova Bay (Ross Sea). The sampling included 42 icefish, 30 emerald rock cod Trematomus bernacchii, 46 striped rock cod $T$. hansoni, 9 dusty rock cod $T$. newnesi and 2 dragonfish. Fish were weighed to the nearest $0.1 \mathrm{~g}$ and measured (fork length, FL) to the nearest $0.1 \mathrm{~cm}$, and gender was determined before parasitological examination. Body condition index $(\mathrm{BCI}$, whole weight/FL ${ }^{3}$ ) was calculated as described by Le Cren (1951) because it is a good indicator of the general well-being of a fish (Bolger \& Connolly 1989).

Musculature, gills, mouth cavity, visceral cavity, digestive tract, liver, heart, gonads and mesenteries of each individual fish were examined under a dissecting microscope for parasites and any associated pathology. For each organ, helminths were counted, washed in physiological saline and fixed in $70 \%$ ethanol. Acanthocephalans, cestodes and digeneans were stained with Mayer's acid carmine and mounted in Canada balsam, while nematodes were mounted in lactophenol cotton blue except in the case of larval Contracaecum spp., which were stored at $-50^{\circ} \mathrm{C}$. Specimens of larval forms associated with pathological changes were deposited in the Italian National Antarctic Museum (MNA, Section of Genoa) accession number; MNA 5230/5234.

\section{Histological analyses}

Tissue samples from selected organs showing gross lesions associated with helminths were fixed in $10 \%$ neutral buffered formalin, embedded in paraffin, sectioned at $6 \mu \mathrm{m}$, and stained with haematoxylin and eosin. Sections from selected cases were also stained with Brown and Brenn Gram's stain and Ziehl-Neelsen methods to detect bacteria and acidfast organisms, respectively.

\section{Parasite DNA extraction from paraffin-embedded tissues}

Fragments of Contracaecum osculatum s.l. larvae from paraffin-embedded stomach and liver were treated and processed for DNA extraction following the procedure described by Shi et al. (2002) and modified by Mattiucci et al. $(2011,2013)$. The removal of paraffin was carried out by adding $1 \mathrm{ml}$ of xylene for $30 \mathrm{~min}$ to the microtube containing the tissue section, followed by 2 washing steps (30 min each) using 100 and $75 \%$ ethanol. The tissue mixture was then washed with phosphate-buffered saline (PBS) for $15 \mathrm{~min}$, which was repeated several times. The lysis buffer (Proteinase K $2 \mathrm{mg} \mathrm{ml}^{-1}, 50 \mu \mathrm{l} ; 1 \mathrm{M}$ Tris-HCl solution, $10 \mu \mathrm{l}$; $0.5 \mathrm{M}$ EDTA, $2 \mu \mathrm{l} ; 10 \%$ sodium dode-

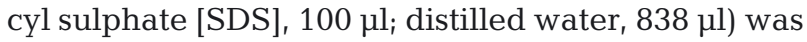
added and the mixture was incubated at $52^{\circ} \mathrm{C}$ overnight. We then added $500 \mu \mathrm{l}$ of phenol, chloroform and isopropanol alcohol, in the proportion 25:24:1, to the de-waxed tissue. The sample was mixed by vortexing and centrifuged at $9450 \times g$ (10 min), and $1 \mathrm{ml}$ of chloroform was added to the supernatant, transferred to an autoclaved microtube and centrifuged at $9450 \times g(5 \mathrm{~min})$. Subsequently, $0.1 \mathrm{ml}$ of $3 \mathrm{M}$ sodium acetate was added, followed by 1 volume of isopropanol, and the mixture was incubated at $-20^{\circ} \mathrm{C}$ overnight. The precipitated DNA was then centrifuged at $8050 \times g$ and then washed with $75 \%$ ethanol. The white pellet was dried at room temperature overnight, or for 15 to $20 \mathrm{~min}$ in a thermoblock. The DNA pellet was suspended in $50 \mu \mathrm{l}$ of TE buffer $\left(\mathrm{pH}\right.$ 8) and then stored at $-20^{\circ} \mathrm{C}$ for the successive steps.

\section{Identification of Contracaecum osculatum s.l. larvae by mtDNA sequencing}

Identification of Contracaecum to the species level was done by sequencing a $629 \mathrm{bp}$ fragment of the mitochondrial cytochrome oxidase 2 (cox2) gene amplified using the primers 211F (5'-TTT TCT AGT TAT ATA GAT TGR TTY AT-3') and 210R (5'-CAC CAA CTC TTA AAA TTA TC-3') (Nadler \& Hudspeth 2000) spanning the mtDNA nucleotide position 
10639 to 11248 , as defined in Ascaris suum (GenBank X54253). Polymerase chain reaction (PCR) amplification was carried out in a volume of $50 \mu \mathrm{l}$ containing $30 \mathrm{pmol}$ of primer, $2.5 \mathrm{mM} \mathrm{MgCl} \mathrm{m}_{2}$ (Amersham Pharmacia Biotech), $1 \times$ PCR buffer (Amersham Pharmacia Biotech), $0.08 \mathrm{mM}$ DMSO, $0.4 \mathrm{mM}$ dNTPs (Sigma-Aldrich), 5 U of Taq Polymerase (Amersham Pharmacia Biotech) and $10 \mathrm{ng}$ of total DNA, according to the procedures detailed by Valentini et al. (2006). The mixture was denatured at $94^{\circ} \mathrm{C}$ for $3 \mathrm{~min}$, followed by 34 cycles at $94^{\circ} \mathrm{C}$ for $30 \mathrm{~s}, 46^{\circ} \mathrm{C}$ for $1 \mathrm{~min}$ and $72^{\circ} \mathrm{C}$ for $1.5 \mathrm{~min}$, followed by elongation at $72^{\circ} \mathrm{C}$ for $10 \mathrm{~min}$. The PCR product was purified using polyethylene glycol precipitation, and automated DNA sequencing was performed by Macrogen Inc. using primers $211 \mathrm{~F}$ and $210 \mathrm{R}$.

The sequences obtained were compared with those from Contracaecum spp. from pinnipeds previously deposited by us in GenBank (Mattiucci et al. 2008). The cox2 sequences were aligned using Clustal X (Thompson et al. 1997).

\section{Statistical analyses}

Statistical analyses were done with sample sizes of at least 30 individual fish, and sufficient fish were available for icefish, emerald rock cod and striped rock cod. Data were organized as individuals $\times$ parasite matrices for each group (i.e. host species), with entries given by the raw intensity data and estimated biomass of parasites following George-Nascimento et al. $(2002,2004)$. Briefly, body sizes of all metazoan parasites inhabiting each fish were quantified for each taxon separately. The body mass of each parasite taxon was expressed as the volume $\left(\mathrm{mm}^{3}\right)$ of a cylinder (nematodes and acanthocephalans), an ellipsoid (digeneans) or a cylinder with an ovoid base (tetraphyllideans). For taxa with large bodies and irregular forms (diphyllobothrideans), we measured the volume of displaced water in a beaker. The number of parasites measured for each taxon consisted of at least 20 specimens; we then estimated the whole volume body mass of each taxon within each host species by multiplying the mean volume body mass of each parasite taxon by the number of the specimens of that taxon in that host.

Data were fourth-root transformed to improve normality and to remove the mean/variance relationship (Santoro et al. 2013). To test the null hypothesis that there were no differences between the parasitic burden observed in different hosts, a distance-based permutational multivariate analysis of variance
(PERMANOVA) was performed (Anderson 2001). The 'adonis' function in the package 'vegan', implemented in the R software environment (R Development Core Team 2011), was used for partitioning distance matrices among sources of variation. Although similar to the classic PERMANOVA, the function 'adonis' was found to be more robust, as it can accept both categorical and continuous variables. We used $\mathrm{BCI}$ as the fixed factor, to test for effects on the intensity and biomass of parasites on body condition in different hosts. Bray-Curtis resemblance matrices were constructed, and significance was tested by performing 999 permutations of both raw intensity and estimated biomass within each group. A bootstrap pairwise $t$-test with 2000 replications (Rózsa et al. 2000) was then used to investigate the differences in parasitic burdens based on both intensity and estimated biomass of parasites between groups (i.e. hosts).

Finally, a similarity percentage (SIMPER) analysis was conducted to examine the contribution to dissimilarity of individual parasite taxa, and multivariate patterns among observations were visualized by means of a non-metric multidimensional scaling ordination (nMDS) based on the Bray-Curtis distances (Kruskal \& Wish 1978).

\section{RESULTS}

All fish studied were adults with mean $( \pm$ SD) FL as follows: icefish (24 females, 18 males) FL: 34 ( \pm 3.102$)$; emerald rock cod (13 females, 17 males) FL: 20.3 $( \pm 2.351)$; striped rock cod (39 females, 7 males) FL: $28( \pm 1.696)$; dusty rock cod ( 3 females, 6 males) FL: 18.4 ( \pm 1.394$)$; dragonfish (2 females) FL: $49.6( \pm 2.263)$.

All fish except 8 striped rock cod and 1 emerald rock cod were infected with helminths. Mean whole intensity of infection was as follows: icefish 1303 helminths per infected fish (range: 486-3727), emerald rock cod 45.5 (range: 10-137), striped rock cod 15.8 (range: 1-76), dusty rock cod 33.4 (range: 6-131), dragonfish 2587 (range: 264-4911).

Larval helminths comprising 5 taxa were associated with pathology including a diphyllobothridean, 2 morphs of tetraphyllideans (cercoids with monolocular bothridia and accessory suckers and cercoids with bilocular bothridia lacking accessory suckers sensu Wojciechowska 1993a), and the nematodes Contracaecum osculatum sp. D and sp. E. Other helminth taxa detected in one or more fish hosts included acanthocephalans (Metacanthocephalus spp. from the intestine and Corynosoma spp. from the body cavity), nematodes (Ascarophis nototheniae 
from the gastrointestinal tract and Contracaecum radiatum from the body cavity) and digeneans from the gastrointestinal tract (Elytrophalloides oatesi, Genolinea bowersi, Gonocerca phycidis, Helicometra spp., Lepidapedon garrardi, Macvicaria spp. and Neolebouria spp.). The proportion of other helminth taxa was $2.7,3.4,8.3,36.2$ and $78.6 \%$ in icefish, dragonfish, dusty rock cod, emerald rock cod and striped rock cod, respectively.

Infection levels are listed in Table 1. The preferred infection sites for larval Contracaecum osculatum spp. were liver and stomach wall in icefish (Fig. 1a,b) and dragonfish, mesentery in emerald and striped rock cod, and liver and mesentery in dusty rock cod. The heaviest infection by C. osculatum spp. was 1031 worms in an icefish, of which 673 were in the liver (approximately 56 specimens per gram of liver), 312 in the stomach wall, and 46 in the mesentery or free in body cavity. In the heaviest infections, the liver was hypertrophic, friable and contained hundreds of nematodes on the surface and within the parenchyma. Marked thickening of the gastric wall was seen associated with several nematodes. C. osculatum spp. were commonly observed free in the stomach lumen or with cephalic or caudal extremities embedded deep into the mucosa, submucosa and muscularis.

The preferred infection sites for diphyllobothridean plerocercoids were liver, mesentery and the stomach wall in icefish (Fig. 1), and mesentery in emerald, striped and dusty rock cod. The heaviest parasitic burden by diphyllobothridean larvae was found in a specimen of icefish infected by 675 worms, including 342 from the stomach wall, 221 from mesentery and 112 from the liver. Mobile white plerocercoids ranging from 0.2 to $1.5 \mathrm{~cm}$ long were easily observed in the coelomic cavity and through the stomach wall (Fig. 1b). Plerocercoids were commonly also seen embedded into the gastric mucosa (Fig. 1c). Older lesions on the gastric mucosa consisted of diffuse white nodules ranging from 0.1 to $0.3 \mathrm{~cm}$ (Fig. 1c), with a core of caseous material with remains of larvae.

The only infection site for tetraphyllidean larvae was the rectum. The heaviest infection was found in a dragonfish which harboured a total of 4678 larvae. Tetraphyllidean larvae associated with lesions included a mixture of at least 2 different forms including cercoids with monolocular and bilocular bothridia.

\section{Molecular identification of Contracaecum osculatum s.l. larvae in fish tissues}

A 629 bp amplicon was obtained from paraffinembedded fragments of Contracaecum osculatum s.l. larvae. A total of 19 specimens associated with gross

Table 1. Prevalence ( $\mathrm{P}_{i}$ percentage of infected fish) and mean intensity ( $\mathrm{I}_{i}$ mean no. of worms per infected fish) of infection (with range in parentheses and $95 \%$ confidence intervals in square brackets when available) of helminth taxa found in 5 species of Antarctic fish from Terra Nova Bay (Ross Sea). -: not applicable (parasite taxon not detected)

\begin{tabular}{|c|c|c|c|c|c|c|c|c|c|c|}
\hline \multirow[t]{2}{*}{ Parasite taxon } & \multicolumn{2}{|c|}{$\begin{array}{c}\text { Chionodraco } \\
\text { hamatus } \\
(\mathrm{n}=42)\end{array}$} & \multicolumn{2}{|c|}{$\begin{array}{c}\text { Cygnodraco } \\
\text { mawsoni } \\
(\mathrm{n}=2)\end{array}$} & \multicolumn{2}{|c|}{$\begin{array}{c}\text { Trematomus } \\
\text { bernacchii } \\
(\mathrm{n}=30)\end{array}$} & \multicolumn{2}{|c|}{$\begin{array}{l}\text { Trematomus } \\
\text { hansoni } \\
(\mathrm{n}=46)\end{array}$} & \multicolumn{2}{|c|}{$\begin{array}{c}\text { Trematomus } \\
\text { newnesi } \\
(\mathrm{n}=9)\end{array}$} \\
\hline & $\mathrm{P}$ & I & $\mathrm{P}$ & I & $\mathrm{P}$ & I & $\mathrm{P}$ & I & $\mathrm{P}$ & I \\
\hline $\begin{array}{c}\text { Contracaecum } \\
\text { osculatum s.l. }\end{array}$ & 100 & $\begin{array}{c}184 \\
(21-1031) \\
{[147-270]}\end{array}$ & 100 & $\begin{array}{c}160.5 \\
(114-207) \\
{[114-160]}\end{array}$ & 33.3 & $\begin{array}{c}3.4 \\
(1-8) \\
{[2.7-12.1]}\end{array}$ & 56.5 & $\begin{array}{c}3.7 \\
(1-18) \\
{[2.92-6.1]}\end{array}$ & 100 & $\begin{array}{c}16 \\
(1-30) \\
{[8.45-22.4]}\end{array}$ \\
\hline Diphyllobothrideans & 100 & $\begin{array}{c}265 \\
(52-675) \\
{[217-322]}\end{array}$ & - & - & 93.3 & $\begin{array}{c}26.5 \\
(1-112) \\
{[19-40.8]}\end{array}$ & 8.7 & $\begin{array}{c}2 \\
(1-3) \\
{[1-2.5]}\end{array}$ & 100 & $\begin{array}{c}5.5 \\
(2-14) \\
{[3.78-8.87]}\end{array}$ \\
\hline Tetraphyllideans & 100 & $\begin{array}{c}815 \\
(37-3427) \\
{[633-1080]}\end{array}$ & 50 & 4678 & 20 & $\begin{array}{c}8 \\
(1-32) \\
{[2-22]}\end{array}$ & 4.3 & $\begin{array}{c}14 \\
(6-22) \\
{[6-22]}\end{array}$ & 44.4 & $\begin{array}{c}22 \\
(1-82) \\
{[1.25-62]}\end{array}$ \\
\hline Acanthocephalans & 38 & $\begin{array}{c}11.7 \\
(1-71) \\
{[5.5-29]}\end{array}$ & 100 & $\begin{array}{c}28 \\
(7-47) \\
{[7-27]}\end{array}$ & 80 & $\begin{array}{c}6.3 \\
(1-27) \\
{[4.53-10]}\end{array}$ & 45.6 & $\begin{array}{c}15.8 \\
(1-56) \\
{[9.36-23.3]}\end{array}$ & 22 & $\begin{array}{c}6 \\
(2-10) \\
{[2-6]}\end{array}$ \\
\hline Other nematodes & 73.8 & $\begin{array}{c}19 \\
(1-7) \\
{[11.6-25.5]}\end{array}$ & - & - & 6.6 & $\begin{array}{c}4.5 \\
(4-5) \\
{[4-4.5]}\end{array}$ & 2 & 3 & - & - \\
\hline Digeneans & 76 & $\begin{array}{c}20.4 \\
(1-135) \\
{[12.9-35.2]}\end{array}$ & 100 & $\begin{array}{c}61 \\
(10-112) \\
{[10-61]}\end{array}$ & 86.6 & $\begin{array}{c}12.2 \\
(1-67) \\
{[9.16-20.9]}\end{array}$ & 39 & $\begin{array}{c}7.6 \\
(1-45) \\
{[4.22-15.5]}\end{array}$ & 44.4 & $\begin{array}{c}3.2 \\
(1-6) \\
{[1.4-4.75]}\end{array}$ \\
\hline
\end{tabular}


lesions were identified by mtDNA $\operatorname{cox} 2$ as $C$. osculatum sp. D and C. osculatum sp. E, which matched previous data (Mattiucci et al. 2008). We detected 9
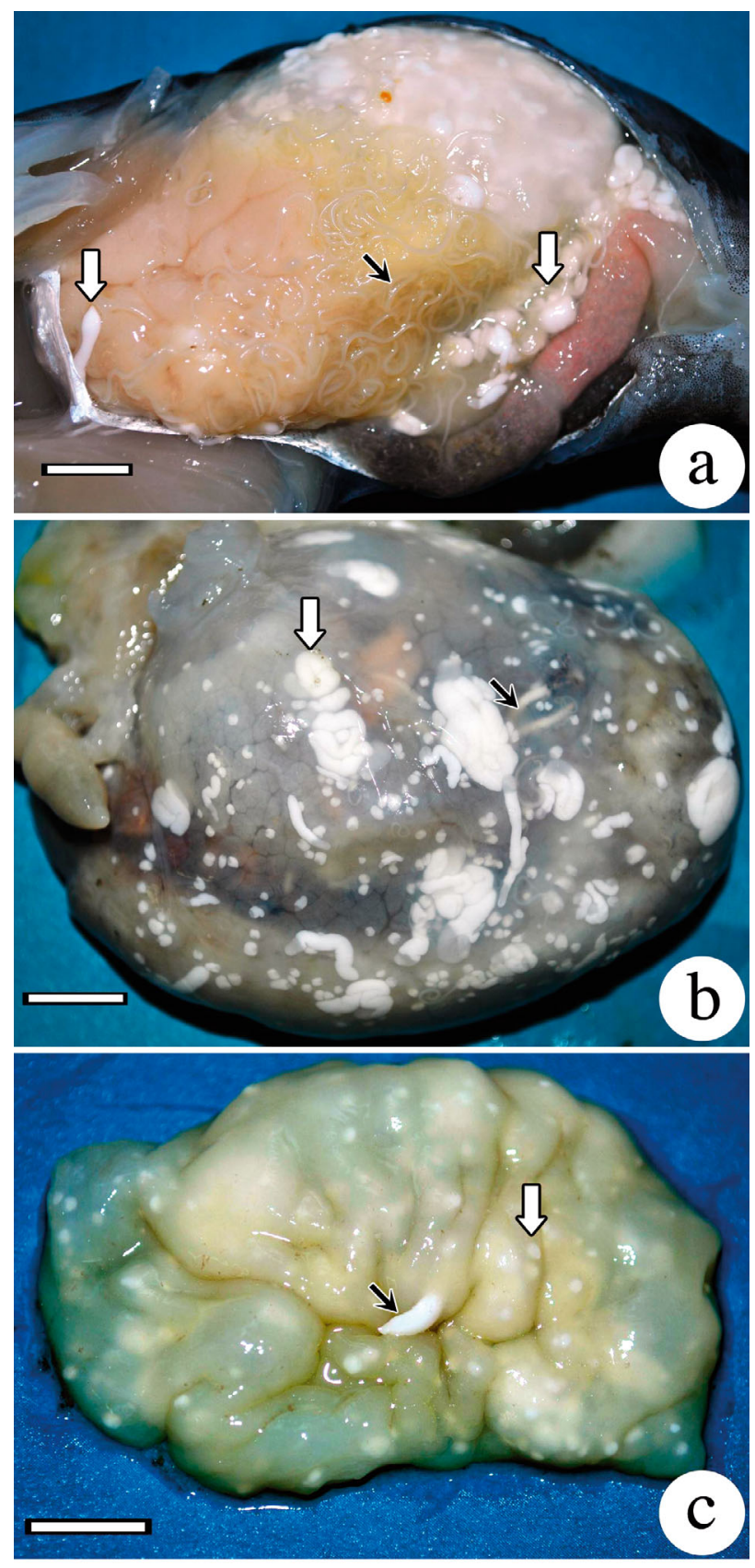

Fig. 1. Chionodraco hamatus. (a) Massive infection by Contracaecum osculatum spp. (black arrow) and diphyllobothridean specimens (thick white arrows) in an icefish. (b) Serosal surface of the stomach, showing mixed infection by C. osculatum spp. (black arrow) and diphyllobothridean specimens (thick white arrow). (c) Mucosal surface of the stomach. Note the nodular whitish lesions caused by diphyllobothridean specimens (thick white arrow). A diphyllobothridean larva (black arrow) is visible, partially embedded in the gastric wall. Scale bars $=1 \mathrm{~cm}$ for all photos larval sp. D and $4 \mathrm{sp}$. E from icefish, 2 larval sp. E in emerald rock cod, $1 \mathrm{sp}$. D in striped rock cod, $1 \mathrm{sp}$. E in dusty rock cod, and $1 \mathrm{sp}$. D and $1 \mathrm{sp}$. E in dragonfish. Mixed infections by both spp. D and E were seen in 4 specimens of icefish. The following accession numbers were deposited to GenBank: C. osculatum $\mathrm{D}$ from icefish (KC412223), from dragonfish (KC 412225) and from striped rock cod (KC412227); C. osculatum E from icefish (KC412224), from dragonfish (KC412226), from emerald rock cod (KC412228) and from dusty rock cod (KC412229).

\section{Histopathological findings}

Histopathological sections were analysed from a total of 19 fish including 13 icefish, 2 dragonfish and 2 emerald, 1 striped and 1 dusty rock cod. All fish showed varying severity of chronic inflammation along with occasional necrosis in the stomach and liver. Of 13 icefish specimens, 2, 4 and 7 had mild, moderate or severe lesions, respectively. Of 2 dragonfish specimens, 1 each had moderate to severe lesions. Of 2 emerald rock cod, 1 had moderate or severe lesions, and a striped rock cod and dusty rock cod had moderate lesions. Mild lesions consisted of mild fibrosis with histiocytes surrounding cross-sections of cestodes and/or nematodes. Moderate lesions consisted of moderate fibrosis and moderate hystiocytic infiltration with occasional erythrophagia associated with helminths. Severe lesions were a more prominent manifestation of inflammation and fibrosis with associated necrosis.

For severe lesions, the stomach and liver were primarily involved. The gastric submucosa was markedly thickened by connective tissue containing infiltrates of histiocytes. Large nidi of necrotic debris were present and surrounded by prominent histiocytic infiltrates mixed with rare granulocytes. Within some of these nidi were cross sections of segmented metazoa consisting of a tegument surrounding a parenchyma with lack of a gut or coelom (diphyllobothridean plerocercoids) or unsegmented metazoa with a lumen and triradiate esophagus (Contracaecum osculatum spp.; Fig. 2a,b). On the hepatic capsular surface and within the parenchyma, there were numerous cross sections of diphyllobothridean plerocercoids (Fig. 2b-d) and C. osculatum s.l. (Fig. 2e). Most parasite sections were surrounded by a thin connective tissue capsule, and occasionally, nearby hepatocytes manifested necrotic changes characterized by cytoplasmic fragmentation, pyknosis and karyorrhexis. Rectal mucosa of Chionodraco hama- 

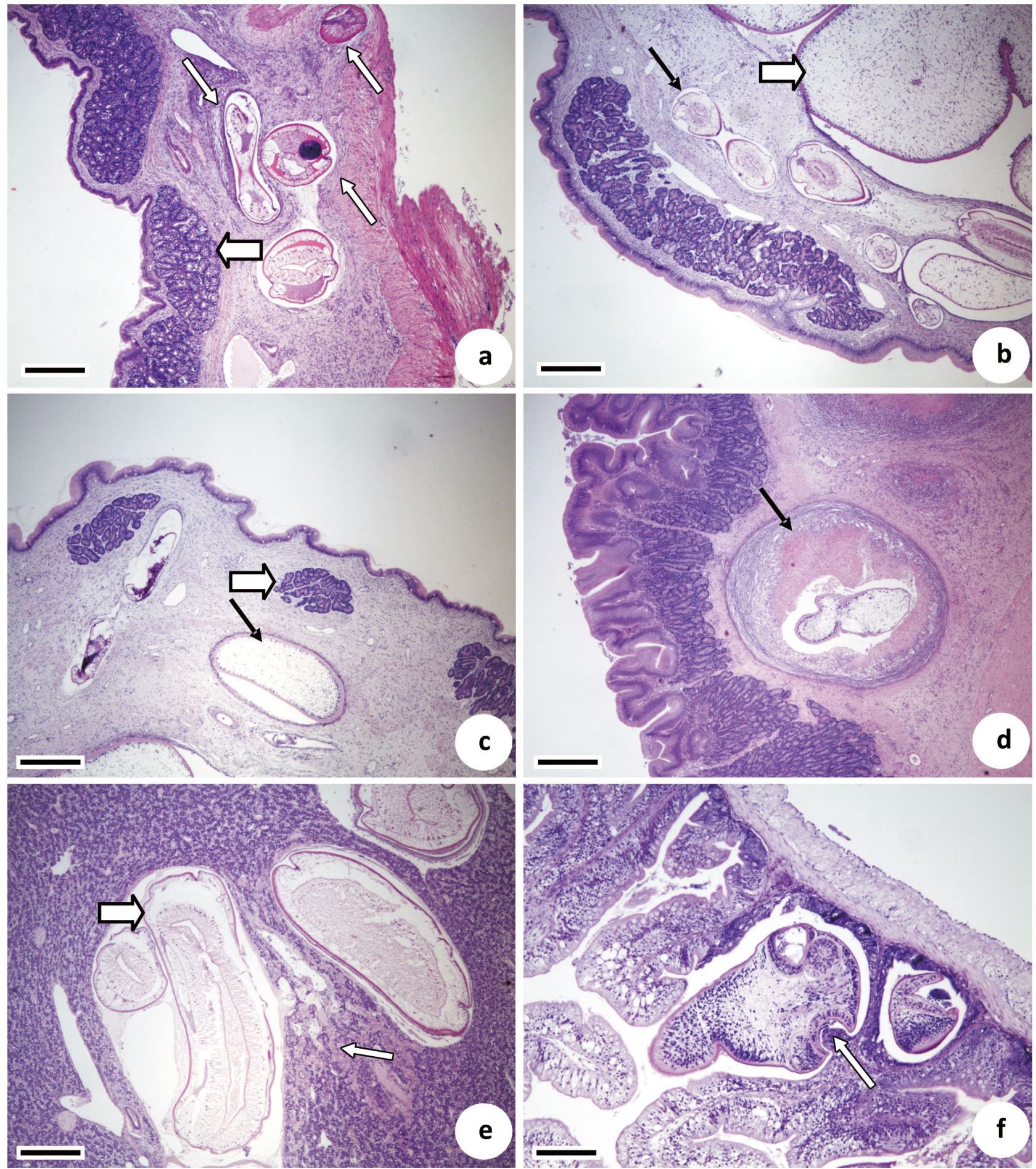

Fig. 2. Chionodraco hamatus. Icefish (a-d) ventriculus, (e) liver, (f) intestines. (a) Icefish with nematodes in muscularis of ventriculus (thin white arrows); serosa on the right and mucosa on the left. Note prominent submucosal glands (thick white arrow). (b) Large cestode (thick white arrow) and nematodes (black arrow) within connective tissue matrix in muscularis; mucosa at lower left. (c) Cestode (black arrow) within markedly thickened connective tissue matrix that effaces submucosal glands (thick white arrow). (d) Cestode within nidus of eosinophilic necrotic debris (black arrow) surrounded by connective tissue capsule; mucosa on left. (e) Nematodes effacing liver parenchyma (thick white arrow). Note lack of inflammatory response and nidi of coagulation necrosis of hepatocytes (thin white arrow). (f) Scolex embedded in mucosa (thin white arrow) of small intestines; serosa top right. Scale bars $=200 \mu \mathrm{m}$ for all photos 
tus and Cygnodraco mawsoni infiltrated by tetraphyllidean cercoids showed moderate multifocal inflammation with multiple scolices attached to the mucosa and plugs of mucosa protruding into the sucker (Fig. 2f).

\section{Statistical analyses}

The whole volume body mass of each parasite taxon found in icefish, striped rock cod and emerald rock cod are listed in Table 2 . The null hypothesis of no differences in the parasitic burden among hosts was rejected when considering both the raw intensity $(F=42.490$, df $=1, \mathrm{p}<0.001)$ and estimated biomass of parasites $(F=33.871$, df $=1, \mathrm{p}<0.001)$. Pairwise comparison showed how the parasitic burden of icefish, measured both on the raw intensity and estimated biomass, differed from those of striped and emerald rock cod $(t=8.231$ and $t=10.210$, respectively, with $\mathrm{p}<0.001$ in both cases), whilst no differences were found between the latter $(t=0.716$, $\mathrm{p}=0.15)$. In other words, parasite infection affected BCI only in icefish, and that was consistent with the point pattern of separation in the nMDS plot (Fig. 3).

SIMPER analysis showed how the raw intensity data of parasitic infection by tetraphyllideans accounted for most of the differentiation between icefish and striped and emerald rock cod ( 58\%), followed by diphyllobothrideans ( 21\%) and Contracaecum osculatum s.l. ( 15\%). However, when considering the estimated biomass, the relative contribution of diphyllobothrideans increased $(\sim 50 \%)$, with C. osculatum s.l. accounting for about $44 \%$ and tetraphyllideans for only $0.15 \%$.

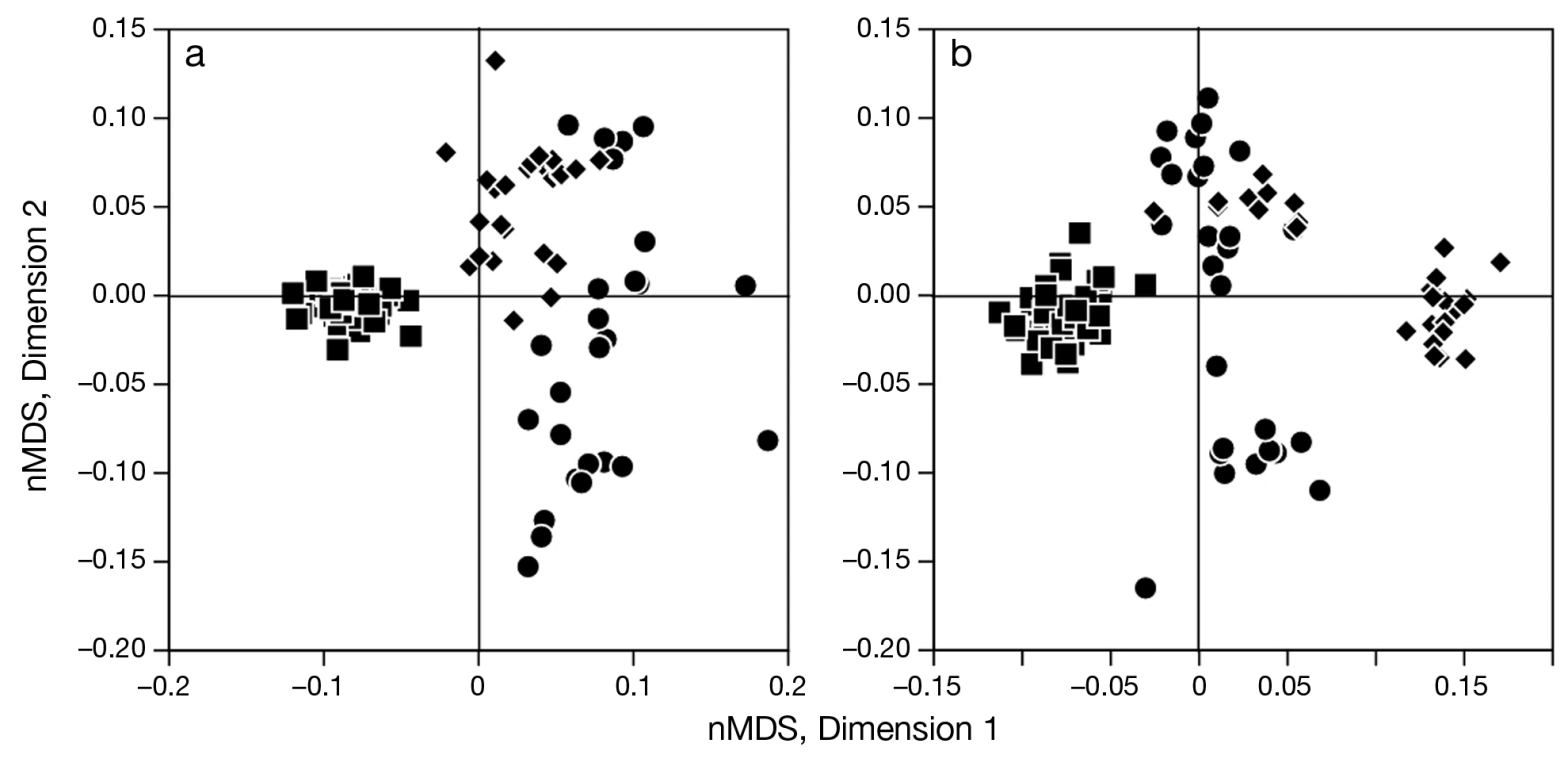

Fig. 3. Chionodraco hamatus, Trematomus hansoni, and T. bernacchii. Nonmetric multidimensional scaling (nMDS) ordination plots of parasitic burden in icefish ( $\square$ ), striped rock cod $(\bullet)$ and emerald rock cod $(\bullet)$ based on (a) the raw intensity data of parasitic infection and (b) estimated biomass. Distances between points represent the difference according to the Bray-Curtis dissimilarity

Table 2. Mean volume body mass $\left(\mathrm{mm}^{3} \pm \mathrm{SD}\right.$; see 'Materials and methods' for details of the calculations) of each parasite taxon found in icefish Chionodraco hamatus, striped rock cod Trematomus hansoni and emerald rock cod T. bernacchii from Terra Nova Bay (Ross Sea)

\begin{tabular}{|lcccccc|}
\hline Host & $\begin{array}{c}\text { Contracaecum } \\
\text { osculatum s.l. }\end{array}$ & Tetraphyllideans & Acanthocephalans & $\begin{array}{c}\text { Other } \\
\text { nematodes }\end{array}$ & Digeneans & $\begin{array}{c}\text { Diphyllo- } \\
\text { bothrideans }\end{array}$ \\
\hline C. hamatus & $1210.519 \pm 1212.642$ & $1319.709 \pm 1170.503$ & $19.605 \pm 70.530$ & $6.863 \pm 7.724$ & $63.012 \pm 106.347$ & $3.814 \pm 2.458$ \\
T. hansoni & $16.309 \pm 21.051$ & $1.323 \pm 6.238$ & $39.905 \pm 71.905$ & $0.789 \pm 4.064$ & $15.942 \pm 34.744$ & $0.0033 \pm 0.011$ \\
T. bernacchii & $12.603 \pm 29.814$ & $0.0241 \pm 0.088$ & $0.0791 \pm 0.109$ & $0.0026 \pm 0.013$ & $0.158 \pm 0.192$ & $0.385 \pm 0.405$ \\
\hline
\end{tabular}




\section{DISCUSSION}

Parasitic infection by larval Contracaecum osculatum s.l., diphyllobothrideans and tetraphyllideans is extensive in fish from Terra Nova Bay. This parasite burden must be supported by an abundant presence of both intermediate/paratenic and definitive hosts in the study area. Molecular-genetic methodologies applied to members of the $C$. osculatum s.l. species complex has demonstrated the presence of 2 Antarctic members, indicated as C. osculatum sp. D and sp. E (Orecchia et al. 1994, Mattiucci \& Nascetti 2008). Fish are documented as paratenic hosts for both anisakid species. The only definitive host identified for these helminths is the Weddell seal Leptonychotes weddellii, in which burdens can reach up to 100000 worms per host within the gastrointestinal tract (Mattiucci \& Nascetti 2008). The common and wide distribution of Weddell seals (Pinkerton et al. 2010) may partly explain the presence of Contracaecum spp. eggs in the environment and the high prevalence of infection in a wide range of fish in the area.

Plerocercoids of Diphyllobothriidae are very common in Antarctic bony fishes; as adults, these parasites occur in seals and birds (Rocka 2003). Johnston (1937) suggested that plerocercoids in Nothothenia coriiceps were Diphyllobothrium quadratum or D. perfoliatum. Unfortunately, matching larval with adult forms has not proved possible so far (Rocka 2003). However, others have identified plerocercoids from Antarctic notothenioids as belonging to Diphyllobothrium spp. (O'Neill et al. 1988, Moser \& Cowen 1991). Life cycles of members of Diphyllobothrium involve crustaceans as first hosts, and bony fish as second and/or paratenic hosts, while birds and marine mammals are the definitive hosts (Bray et al. 1994). Like Contracaecum spp., it is possible that the Weddell seal plays a role in the high prevalence of infection of this parasite taxon in a wide range of fish.

Tetraphyllidean cestodes show a wide degree of host specificity, with elasmobranch and holocephalid fish as definitive hosts, and unknown crustaceans as first intermediate hosts (Euzet 1994). Cercoids of tetraphyllideans with monolocular bothridia belong to the genus Phyllobothrium, parasitizing adult sharks and skates (Wojciechowska 1993a), while cercoids with bilocular bothridia lacking accessory suckers belong to the family Phyllobothriidae (Prudhoe 1969, Holloway \& Spence 1980, Skryabin \& Yurakhno 1987, Wojciechowska 1993a) or Oncobothriidae (Avdeeva 1989). Probably the most suitable definitive hosts for these larval forms of tetraphyllideans are skates. In contrast to sharks, which are absent from the Ross Sea (Ainley et al. 2006), we suspect that the relatively abundant skates may be responsible for circulation of tretraphyllideans to the host fishes studied here.

Pathological changes induced by helminths and the correlation between parasitic infection and the general health status of the fish hosts have never been described in Antarctic teleosts. Hoogesteger \& White (1981) reported a 'small deleterious effect' of endoparasites on Notothenia neglecta from Signy Island (South Orkney Islands, Antarctica) but provided no microscopic pathological evidence. A condition factor linked to gonad-free body weight varied inversely with fish size, and there was a positive correlation between the $\mathrm{BCI}$ and the level of infection of endoparasites (Hoogesteger \& White 1981). Our results obtained here demonstrate that larvae may cause histological lesions ranging from mild to severe in all examined host species. The icefish was the most infected species, with a mean intensity of infection of 1303 worms per fish. It was also infected by the larger helminths including diphyllobothrideans and Contracaecum osculatum s.l., which were the second and third most abundant taxa after the tetraphyllideans. Helminth burden (including number and biomass of helminths) and BCI were strongly correlated in icefish but not in emerald and striped rock cod, which had a lower intensity of infection. Thus, our pathology findings along with negative association between BCI and parasite burdens suggests that diphyllobothridean and anisakid helminths are adversely affecting the health of icefish but not that of emerald and striped rock cod.

The level of infection, the size of the parasite and the tissue or organ affected can influence host responses. These can range from benign encapsulation of the pathogen by host cells, to acute and chronic inflammation and necrosis (Williams \& Jones 1994, Secombes \& Chappell 1996). Site of infection also plays an important role in the degree of damage caused by endoparasites and their effects on body condition and survival (Seppänen et al. 2009, Khan 2012). In icefish, larval diphyllobothrideans and Contracaecum osculatum s.l. induced marked pathological changes penetrating the muscularis layer of stomach and hepatic tissue in both light and heavy infections. The significant lesions in the liver due to abundant and voluminous helminths likely compromised the function of this organ and may have contributed to poor body condition in icefish. On the other hand, diphyllobothrideans and C. osculatum s.l. in emerald and striped rock cod were found 
mainly in the body cavity and in small numbers compared to icefish. In general, a larger worm was more damaging to its host, and this was reflected by larger taxa such as diphyllobothrideans and C. osculatum s.l., which together contributed about $94 \%$ of adverse effect on the BCI of icefish, whereas the smaller tetraphyllideans contributed only $0.15 \%$.

Larvae of diphyllobothrideans and Contracaecum osculatum s.l. are large, and several individuals can cause severe mechanical damage (Williams \& Jones 1994). In whiting Merlangius merlangus, Contracaecum spp. larvae penetrated liver tissue and became encapsulated within the parenchyma, destroying liver cells, blood vessels and bile ducts with attendant inflammation with heterophils, macrophages and fibroblasts and deposition of melanin around the connective tissue capsule (Elarifi 1982). O'Neill et al. (1988) described the chronic inflammatory response in the body cavity of juvenile silverfish to plerocercoids identified as Diphyllobothrium spp. with burdens ranging from 4 to 17 larvae. Host response to the parasite was characterized by a discrete inflammatory sheath. A collagenous connective tissue containing fibroblasts formed the bulk of the sheath, which was infiltrated by a blood vascular network and leucocytes, mainly monocytes/macrophages. This was observed at the host-parasite interface, where many leucocytes contained periodic acidSchiff-positive particles and pigment granules (O'Neill et al. 1988). Salmo clarki infected by Diphyllobothrium cordiceps had necrosis with oedema (Otto \& Heckman 1984). The effects of parasites on longer-term survival await further investigations.

Pathological changes observed on the mucosal surface of the rectum due to tetraphyllideans are either the results of mechanical damage by the attachment organs with inflammatory response at the attachment site or their effects on inhibiting absorption of nutrients through the gut mucosa. Intensity of the response appears to be directly related to the thousands of parasites on a restricted area of mucosa corresponding to approximately $1 \mathrm{~cm}$.

Intraspecific susceptibility to infection and host diet should explain different patterns of infection and related pathological changes found in the different fish species examined (Poulin 2007, Lagrue et al. 2011). A number of host-related factors have been proposed to account for differences in parasite infection patterns among vertebrates, of which factors related to host body size often play a prominent role (Poulin 2007). The largest predatory fish such as dragonfish and icefish probably show the heaviest helminth burden compared to the Trematomus spp. because they are likely exposed through predation on multiple intermediate hosts such as invertebrates and smaller fish (see La Mesa et al. 2004). On the other hand, the heaviest burden of those larval parasites might suggest that the icefish represents the predominant prey for the vertebrates in which the adult forms of those parasites develop.

Acknowledgements. This study was supported by the Italian Project PRNA 2009 (Italian Ministry of Education and Research-MIUR) 'Spatial-temporal genetic diversity of endoparasites in polar regions: an approach to the study of the impact of global changes on the marine trophic webs'. Mention of products or trade names does not imply endorsement by the US Government.

\section{LITERATURE CITED}

Ainley D, Toniolo V, Ballard G, Barton K and others (2006) Managing ecosystem uncertainty: critical habitat and dietary overlap of top-predators in the Ross Sea. CCAMLR document EMM 06-07. Commission for the Conservation of Antarctic Marine Living Resources, Hobart

Anderson MJ (2001) A new method for non-parametric multivariate analysis of variance. Aust J Ecol 26:32-46

Avdeeva NV (1989) On the generic belonging of three types of larvae of cestodes of the collective genus 'Scolex'. Parazitologiya 23:351-355 (in Russian)

Bolger T, Connolly PL (1989) The selection of suitable indices for the measurement and analysis of fish condition. J Fish Biol 34:171-182

Bray RA, Jones A, Andersen KI (1994) Order Pseudophyllidea Carus, 1863. In: Khalil LF, Jones A, Bray RA (eds) Keys to the cestode parasites of vertebrates. CAB International, Wallingford, p 205-247

- Elarifi AE (1982) The histopathology of larval anisakid nematode infections in the liver of whiting, Merlangius merlangus (L.), with some observations on blood leucocytes of the fish. J Fish Dis 5:411-419

Euzet L (1994) Order Tetraphyllidea Carus, 1863. In: Khalil LF, Jones A, Bray RA (eds) Keys to the cestode parasites of vertebrates. CAB International, Wallingford, p 149-194

> George-Nascimento M, Garcías F, Muñoz G (2002) Parasite body volume and infracommunity patterns in the southern pomfret Brama australis (Pisces: Bramidae). Rev Chil Hist Nat 75:835-839

> George-Nascimento M, Muñoz G, Marquet PA, Poulin R (2004) Testing the energetic equivalence rule with helminth endoparasites of vertebrates. Ecol Lett 7 : 527-531

Holloway HL, Spence JA (1980) Ecology of animal parasites in McMurdo Sound, Antarctica. Comp Physiol Ecol 5: 262-284

Hoogesteger JN, White MG (1981) Note on parasite infestation of inshore fist at Signy Island, South Orkney Islands. Br Antarct Surv Bull 54:23-31

Johnston TH (1937) Cestoda. Aust Antarct Exped Sci Rep Ser C 10:1-74

Khan RA (2012) Host-parasite interactions in some fish species. J Parasitol Res 2012:237280 
Kruskal JB, Wish M (1978) Multidimensional scaling. Sage Publications, Beverly Hills, CA

> La Mesa M, Eastman JT, Vacchi M (2004) The role of notothenioid fish in the food web of the Ross Sea shelf waters: a review. Polar Biol 27:321-338

Lagrue C, Kelly DW, Hicks A, Poulin R (2011) Factors influencing infection patterns of trophically transmitted parasites among a fish community: host diet, host-parasite compatibility or both? J Fish Biol 79:466-485

Laskowski Z, Zdzitowiecki K (2005) The helminth fauna of some notothenioid fishes collected from the shelf of Argentine Islands, West Antarctica. Pol Polar Res 26: 315-324

> Le Cren ED (1951) The length-weight relationship and seasonal cycle in gonad weight and condition in the perch (Perca fluviatilis). J Anim Ecol 20:201-209

Mattiucci S, Nascetti G (2008) Advances and trends in the molecular systematics of anisakid nematodes, with implications for their evolutionary ecology and host-parasite co-evolutionary processes. Adv Parasitol 66:47-148

Mattiucci S, Paoletti M, Oliverio-Verbel J, Baldiris R and others (2008) Contracaecum bioccai n. sp. from the brown pelican Pelecanus occidentalis (L.) in Colombia (Nematoda: Anisakidae): morphology, molecular evidence and its genetic relationship with congeners from fish-eating birds. Syst Parasitol 69:101-121

Mattiucci S, Paoletti M, Borrini F, Palumbo M and others (2011) First molecular identification of the zoonotic parasite Anisakis pegreffii (Nematoda: Anisakidae) in a paraffin-embedded granuloma taken from a case of human intestinal anisakiasis in Italy. BMC Infect Dis 11:82-88

Mattiucci S, Fazii P, De Rosa A, Paoletti M and others (2013) Anisakiasis and gastroallergic reaction associated with Anisakis pegreffii infection, Italy. Infect Dis 19:496-499

Moser M, Cowen RK (1991) The effects of periodic eutrophication on parasitism and stock identification of Trematomus bernacchii (Pisces: Nototheniidae) in McMurdo Sound, Antarctica. J Parasitol 77:551-556

Nadler SA, Hudspeth DSS (2000) Phylogeny of the Ascaridoidea (Nematoda: Ascaridida) based on three genes and morphology: hypotheses of structural and sequence evolution. J Parasitol 86:380-393

O'Neill JG, White MG, Sims TA, Barber DL (1988) An inflammatory response of the Antarctic silverfish, Pleuragramma antarcticum Boulenger 1902 (Teleostei: Notothenioidei), to the infestation by the plerocercoid of a pseudophyllidean cestode (Diphyllobothrium sp.). $\mathrm{Br}$ Antarct Surv Bull 79:51-63

Orecchia P, Mattiucci S, D'Amelio S, Paggi L and others (1994) Two new members in the Contracaecum osculatum complex (Nematoda, Ascaridoidea) from the Antarctic. Int J Parasitol 24:367-377

Otto TN, Heckmann RA (1984) Host tissue response for trout infected with Diphyllobothrium cordiceps larvae. Great Basin Nat 44:125-131

Pinkerton MH, Bradford-Grieve JM, Hanchet SM (2010) A balanced model of the food web of the Ross Sea, Antarctica. CCAMLR Sci 17:1-31

Poulin R (2007) Evolutionary ecology of parasites. Princeton University Press, Princeton, NJ
Prudhoe S (1969) Cestodes from fish, birds and whales. Brit Aust NZ Antarct Res Exped Rep Ser B 8:171-193

R Development Core Team (2011) R: a language and environment for statistical computing. R Foundation for Statistical Computing, Vienna

Rocka A (2003) Cestodes of the Antarctic fishes. Pol Polar Res 24:261-276

> Rocka A (2006) Helminths of Antarctic fishes: life cycle biology, specificity and geographical distribution. Acta Parasitol 51:26-35

Rózsa L, Reiczigel J, Majoros G (2000) Quantifying parasites in samples of hosts. J Parasitol 86:228-232

Santoro M, Aznar FJ, Mattiucci S, Kinsella JM, Pellegrino F, Cipriani P, Nascetti G (2013) Parasite assemblages in the Western whip snake Hierophis viridiflavus carbonarius (Colubridae) from southern Italy. J Helminthol, doi: 10.1017/S0022149X12000338

> Secombes CJ, Chappell LH (1996) Fish immune responses to experimental and natural infection with helminth parasites. Annu Rev Fish Dis 6:167-177

Seppänen E, Kuukka H, Voutilainen A, Huuskonen H, Peuhkuri N (2009) Metabolic depression and spleen and liver enlargement in juvenile Arctic charr Salvelinus alpinus exposed to chronic parasite infection. J Fish Biol 74:553-561

Shi SR, Cote RJ, Wu L, Liu C and others (2002) DNA extraction from archival formalin-fixed, paraffin-embedded tissue sections based on the antigen retrieval principle: heating under the influence of $\mathrm{pH}$. J Histochem Cytochem 50:1005-1011

Skryabin AS, Yurakhno MV (1987) The first finding of larvae of Scolex pleuronectis in pinnipeds. Parazitologiya 21:743-744 (in Russian)

Thompson JD, Gibson TJ, Plewniak F, Jeanmougin F, Higgins DG (1997) The Clustal X windows interface: flexible strategies for multiple sequence alignment aided by quality analysis tools. Nucleic Acids Res 25:4876-4882

> Valentini A, Mattiucci S, Bondanelli P, Webb SC, MignucciGiannone A, Colom-Llavina MM, Nascetti G (2006) Genetic relationships among Anisakis species (Nematoda: Anisakidae) inferred from mitochondrial cox-2 sequences, and comparison with allozyme data. J Parasitol 92:156-166

Williams H, Jones A (1994) Parasitic worms of fish. Taylor \& Francis, London

Wojciechowska A (1993a) The tetraphyllidean and tetrabothriid cercoids from Antarctic bony fishes. I. Morphology. Identification with adult forms. Acta Parasitol 38: $15-22$

Wojciechowska A (1993b) The tetraphyllidean and tetrabothriid cercoids from Antarctic bony fishes. II. Occurrence of cercoids in various fish species. Acta Parasitol 38:113-118

Wojciechowska A, Zdzitowiecki K, Pisano E, Vacchi M (1994) The tetraphyllidean cercoids from bony fishes occurring in the Ross Sea (Antarctic). Acta Parasitol 39: $13-15$

Zdzitowiecki K (2001) New data on the occurrence of fish endoparasitic worms off Adelie Land, Antarctica. Pol Polar Res 22:159-165

Submitted: January 3, 2013; Accepted: May 29, 2013

Proofs received from author(s): July 11, 2013
Editorial responsibility: David Marcogliese, Montreal, Quebec, Canada 